\title{
Contribution of Visible Surface Mold to Airborne Fungal Concentration as Assessed by Digital Image Quantification
}

\author{
Chun-Chieh Tseng ${ }^{1}\left(\mathbb{D}\right.$, Ning Huang $^{2}$, Chia-Jung Hsieh ${ }^{1}$, Chien-Che Hung ${ }^{1}\left(\mathbb{D}\right.$ and Yue-Liang Leon Guo ${ }^{2,3, *(\mathbb{D})}$ \\ 1 Department and Graduate Institute of Public Health, Tzu Chi University, Hualien 97004, Taiwan; \\ tsengcc@mail.tcu.edu.tw (C.-C.T.); cjhsieh@mail.tcu.edu.tw (C.-J.H.); gavink23@gmail.com (C.-C.H.) \\ 2 Institute of Environmental and Occupational Health Sciences, College of Public Health, \\ National Taiwan University, Taipei 10617, Taiwan; r95841018@ntu.edu.tw \\ 3 Environmental and Occupational Medicine, National Taiwan University College of Medicine and NTU \\ Hospital, Taipei 10617, Taiwan \\ * Correspondence: leonguo@ntu.edu.tw
}

Citation: Tseng, C.-C.; Huang, N.; Hsieh, C.-J.; Hung, C.-C.; Guo, Y.-L.L. Contribution of Visible Surface Mold to Airborne Fungal Concentration as Assessed by Digital Image Quantification. Pathogens 2021, 10, 1032. https://doi.org/10.3390/ pathogens 10081032

Academic Editor: Donát Magyar

Received: 21 June 2021

Accepted: 13 August 2021

Published: 15 August 2021

Publisher's Note: MDPI stays neutral with regard to jurisdictional claims in published maps and institutional affiliations.

Copyright: () 2021 by the authors. Licensee MDPI, Basel, Switzerland. This article is an open access article distributed under the terms and conditions of the Creative Commons Attribution (CC BY) license (https:// creativecommons.org/licenses/by/ $4.0 /)$.
Abstract: The rapid monitoring of total fungi, including air and surface fungal profiling, is an important issue. Here, we applied air and surface sampling, combined with digital image quantification of surface mold spots, to evaluate the contribution of surface fungi to airborne fungal concentrations. Cladosporium, Penicillium, Aspergillus, and yeast often appeared in the air or on wall surfaces during sampling. The indoor/outdoor concentration ratios (I/O ratios) demonstrated that the airborne concentrations of commonly found fungal genera outdoors were higher than those indoors (median $\mathrm{I} / \mathrm{O}$ ratio $=0.65-0.91$ ), excluding those of Penicillium and yeast. Additionally, the surface density (fungal concentration/area) of individual fungi showed no significant correlation with the airborne concentration, excluding that of Geotrichum. However, if a higher surface ratio $(>0.00031)$ of mold spots appeared in the total area of an indoor environment, then the concentrations of Aspergillus and Geotrichum in the air increased significantly. Our results demonstrated that the airborne concentration of indoor fungi is significantly correlated with the outdoor concentration. A higher density of surface fungi does not necessarily contribute to a high fungal concentration in the air. In contrast to fungal density, quantification of the surface fungal area is recommended to assess the risk of surface fungi propelling into the air.

Keywords: bioaerosol; fungi; surface; indoor air

\section{Introduction}

Fungal spores are ubiquitous in indoor environments and often present as mixtures of fungal genera. Although fungal types and concentrations in nonproblematic indoor environments are considered to originate primarily from outdoor air [1-3], mold contamination on wall surfaces may also affect fungal concentrations in indoor air [4]. Especially in cases when water damage or moisture accumulation appears on walls, molds that rapidly colonize surfaces may propel into the indoor air with airflow or external force and further affect the air quality [4]. To date, several studies have demonstrated the relationship between fungal exposure and allergic symptoms, including night cough, wheezing, dyspnea, and allergic rhinitis $[5,6]$. Therefore, an efficient fungus monitoring method is needed to explore the total amount of human exposure to fungi; such a method should consider the fungal profile both in the air and on the surfaces of indoor environments.

To identify the potential fungal reservoir, comparisons between indoor/outdoor fungal concentrations in the air have been used to document the presence of fungal contamination. In Taiwan, 2.9 to $31.4 \%$ of residential environments have indoor/outdoor concentration ratios (I/O ratios) higher than one for specific fungal species, including Aspergillus spp., Penicillium spp., Cladosporium spp., Alternaria spp., and yeast [7]. Thus, 
the concentration of fungi in indoor air may not originate solely from outdoor air. The potential fungal reservoir may be derived from wall surfaces or house dust $[8,9]$.

At present, although different sampling and analysis methods are available, there are still no widely acceptable standard protocols for measuring fungi in indoor environments. Sampling methods can be divided into air and surface sampling. Air sampling is commonly used to determine the fungal concentration and composition in the air by an active/passive sampling apparatus [10]. Surface sampling has been applied to identify localized surface mold contamination problems with cotton swabs, direct sampling with tapes, or Rodac (Replicating Organism Direct Agar Contact) plates [4,10]. Although a previous study suggested that air and surface sampling should be combined to obtain a robust result, it was also indicated that there was no strong correlation between the results obtained from air and surface testing [10]. While these results may be related to the different sampling methods used, they may also imply that the correlation between air and surface fungi is species dependent, since no species identification was conducted in this study [10].

In practice, almost all surface sampling addresses only the mold density on the surface per area (e.g., CFU $/ \mathrm{cm}^{2}$ ) [11], and very limited studies have quantified the area of mold growth on surfaces. The discovery of visible mold growth on a surface warrants a recommendation for cleanup and investigation of the possible reason for the growth [1]. However, some difficulties in correctly determining the mold surface area have to be overcome, especially when the surfaces are small or have a nonuniform shape. Conversely, mold spores can be divided into wet spores and dry spores. A previous study indicated that dry spores, including those of Penicillium, Aspergillus, and Cladosporium, can be easily propelled into the air, whereas wet spores, such as those of Stachybotrys, Acremonium, and Trichoderma, are considered to produce mucilaginous masses that stick firmly to surfaces [4]. Consequently, the ability of fungi to float from the surface into the air could be related to the hydrophilic or hydrophobic properties of spores. In addition, relative humidity has also been found to directly influence the release of conidia from conidiophores [2].

To understand the contribution of wall fungi to the concentration of airborne fungi in residential environments, the aims of this investigation were (1) to evaluate the correlation between the environmental factors and airborne/surface fungi in the residential environment; (2) to determine the correlation among the fungal concentrations recovered from outdoor, indoor, and surface sampling; (3) to apply a simple digital image quantification method for calculating the total mold surface area and then use this indicator to evaluate the surface mold ratio, with a greater emphasis on airborne fungal concentrations.

\section{Results}

\subsection{Temperature, Relative Humidity, and Wind Speed in Indoor Environments}

The average atmospheric temperature and relative humidity $(\mathrm{RH})$ were $30.0^{\circ} \mathrm{C}$ (from 25.1 to $36.2^{\circ} \mathrm{C}$ ) and $67.6 \%$ (from 45.3 to $88.8 \%$ ) throughout the sampling periods, respectively. In addition, the average surface temperature was $31.4^{\circ} \mathrm{C}$ (from 27.82 to $36.8^{\circ} \mathrm{C}$ ), and the mean surface RH was $68.2 \%$ (from $37.9 \%$ to $89.93 \%$ ). Two other environmental parameters, the $\mathrm{CO}_{2}$ concentrations (average $=632 \mathrm{ppm}$; from 400 to $1200 \mathrm{ppm}$ ) and wind speed (average $=0.2 \mathrm{~m} / \mathrm{s}$; from 0 to $1.45 \mathrm{~m} / \mathrm{s}$ ), were also measured.

\subsection{Concentrations of Airborne Fungi in Indoor and Outdoor Air}

Figure 1 shows the airborne fungal concentration in the indoor air (including the living room and bedroom air; Figure 1A,B) and outdoor air (Figure 1C). There was no significant difference in the total concentration of airborne fungi between indoor $\left(\right.$ median $\left.=278.0 \mathrm{CFU} / \mathrm{m}^{3}\right)$ and outdoor air $\left(\right.$ median $\left.=313.3 \mathrm{CFU} / \mathrm{m}^{3} ; p=0.309\right)$. However, the fungal concentrations in the indoor air were significantly lower than those in the outdoor air for Cladosporium ( $p=0.038)$, Aspergillus ( $p=0.003)$, and Fusarium $(p=0.024)$. Only the concentration of yeast was found to be significantly higher in indoor air than in outdoor air $(p=0.012)$. Due to the low detection rates of Geotrichum $(12-15 \%)$ and Verticillium $(3.88 \%)$, the concentrations of these two fungi are not presented in Figure 1. 
Based on the distribution of fungal concentrations, the most predominant fungal genera, with higher concentrations, were Cladosporium, yeast, Penicillium, Aspergillus, and Fusarium, regardless of indoor or outdoor air. Cladosporium ranked first, with more than $98 \%$ of house samples containing Cladosporium (Figure 1D,E). In addition to Cladosporium, more than $65 \%$ of household air samples contained Aspergillus, Penicillium, and yeast.

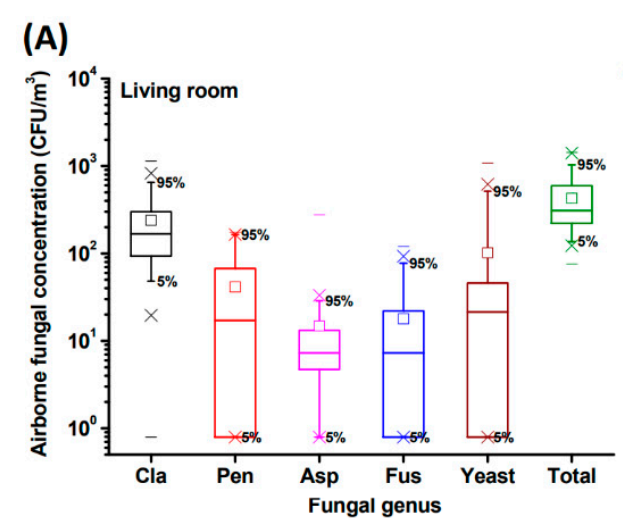

(D) Indoor

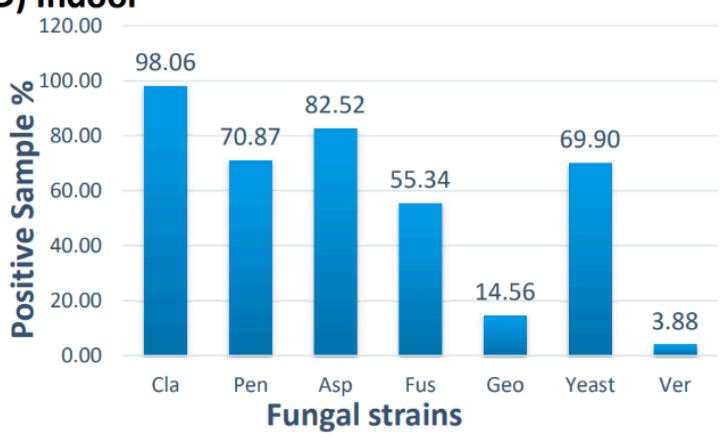

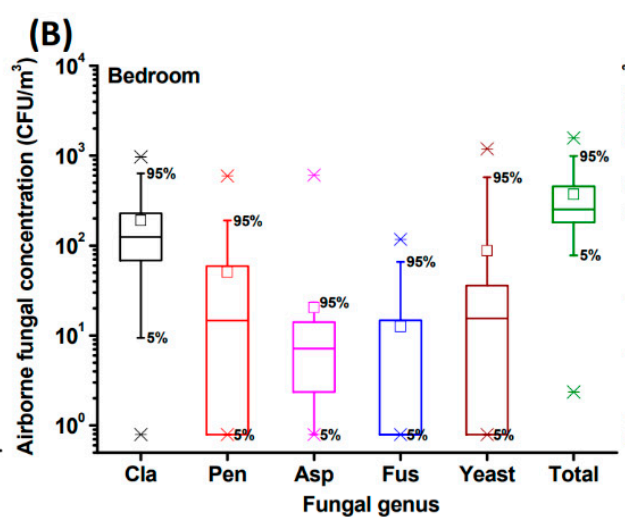

(C)

(E)Outdoor
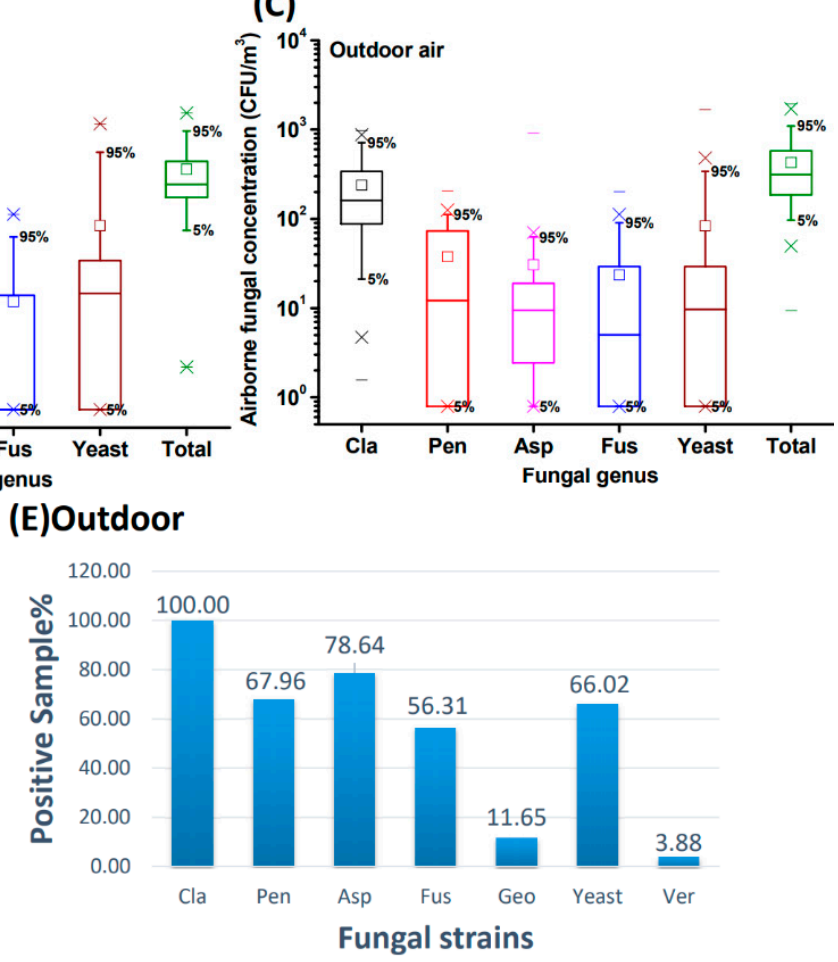

Figure 1. The concentration $\left(\mathrm{CFU} / \mathrm{m}^{3}\right)$ distribution of different fungal genera in the indoor air of living rooms (A) and bedrooms (B) and in outdoor air (C). Figures (D,E) show the \% positive samples having the respective fungal genera in the indoor air (D) and outdoor air (E) of 103 household samples. Cla = Cladosporium; Pen = Penicillium; Asp = Aspergillus; Fus = Fusarium; Geo = Geotrichum; Ver $=$ Verticillium. The square $\square$ is the average value of the individual fungal genus .

To identify potential sources of biological contamination, the specific concentrations of indoor and outdoor airborne fungi have often been compared [7,12]. Consequently, we calculated the I/O ratio for almost all fungal genera recovered from the air (except for Geotrichum and Verticillium) (Figure 2). In addition, due to the low detection rate of Geotrichum and Verticillium, the I/O ratios of these two fungi are not presented in Figure 2. Furthermore, if the corresponding fungus was not detected in the airborne sample, then this sample was excluded from the I/O ratio calculation. Since the concentration of fungi in household air samples varied greatly, we used the median to represent the I/O ratio. Except for Penicillium $(\mathrm{I} / \mathrm{O}=1.002)$, yeast $(\mathrm{I} / \mathrm{O}=1.56)$, and total fungi $(\mathrm{I} / \mathrm{O}=1.01)$, the $\mathrm{I} / \mathrm{O}$ ratios of the fungal genera recovered from the air were less than 1 (Figure 2).

\subsection{Concentrations of Surface Fungi in Indoor Environments}

There were no visible mold spots on the surfaces of some resident environments $(n=56)$. Figure 3 shows the distribution of the surface fungal concentration in environments where visible mold spots were present $(n=47)$. Figure 3 A shows that the median total fungal concentration on household wall surfaces was $340.0 \mathrm{CFU} / \mathrm{cm}^{2}$. Except for Fusarium, fungal genera that appeared on wall surfaces also appeared in the air. Because the detection rate of certain fungi was low (Figure 3C), Figure 3B does not use the arithmetic mean or median to represent the concentration of individual surface fungi; it is only presented in terms of the proportion of the respective fungal genus to the total fungal concentration. The most predominant fungal genera on the wall surface were Cladosporium and yeast. 
These two major fungal genera accounted for more than $80 \%$ of the total surface fungi, and their concentrations varied widely from N.D. (not detected) to $10,253.3 \mathrm{CFU} / \mathrm{cm}^{2}$. In addition, approximately $49 \%$ of the household samples contained Cladosporium and yeast (Figure 3C). Among household samples where mold spots appeared on the surface, $68 \%$ of the samples had only one fungal genus, $17 \%$ of the samples contained two genera of fungi, and only $14 \%$ of the identified samples contained more than three fungal genera. The diversity of fungal genera contained in the mold spots was lower than that in air samples.

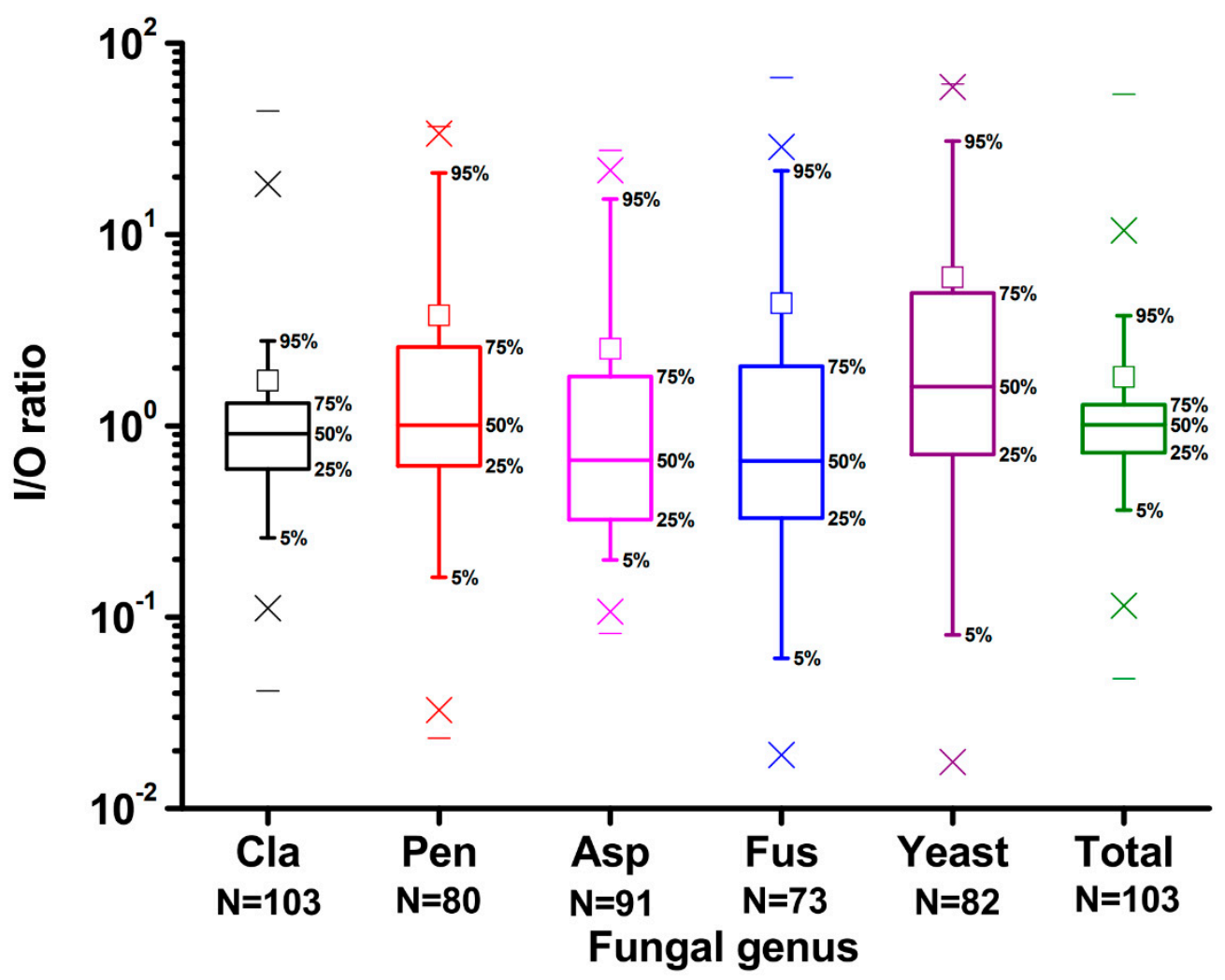

Figure 2. The indoor/outdoor concentration ratios (I/O ratios) for different fungal genera recovered from the air. The square $\square$ above the box is the average value of the individual fungal genus. $\mathrm{Cla}=$ Cladosporium; Pen = Penicillium; Asp = Aspergillus; Fus = Fusarium $;$ Total $=$ total fungi .

\subsection{Correlation among Environmental Parameters and Airborne Fungal Concentrations}

As shown in Table 1, the correlation among the environmental parameters (temperature, atmospheric $\mathrm{RH}$, wind speed, and $\mathrm{CO}_{2}$ ) and airborne fungal concentrations in the indoor environment was determined by Spearman's rank correlation. Cladosporium, Fusarium, and Verticillium in indoor air were significantly correlated with temperature. In addition, the airborne concentrations of Penicillium were significantly related to high $\mathrm{RH}$. However, Fusarium and Verticillium were negatively correlated with RH. Only Verticillium was correlated with wind speed. For $\mathrm{CO}_{2}$, all statistically significant correlations were negative correlations for the concentrations of airborne Cladosporium, Aspergillus, Fusarium, Verticillium, and total fungi. 


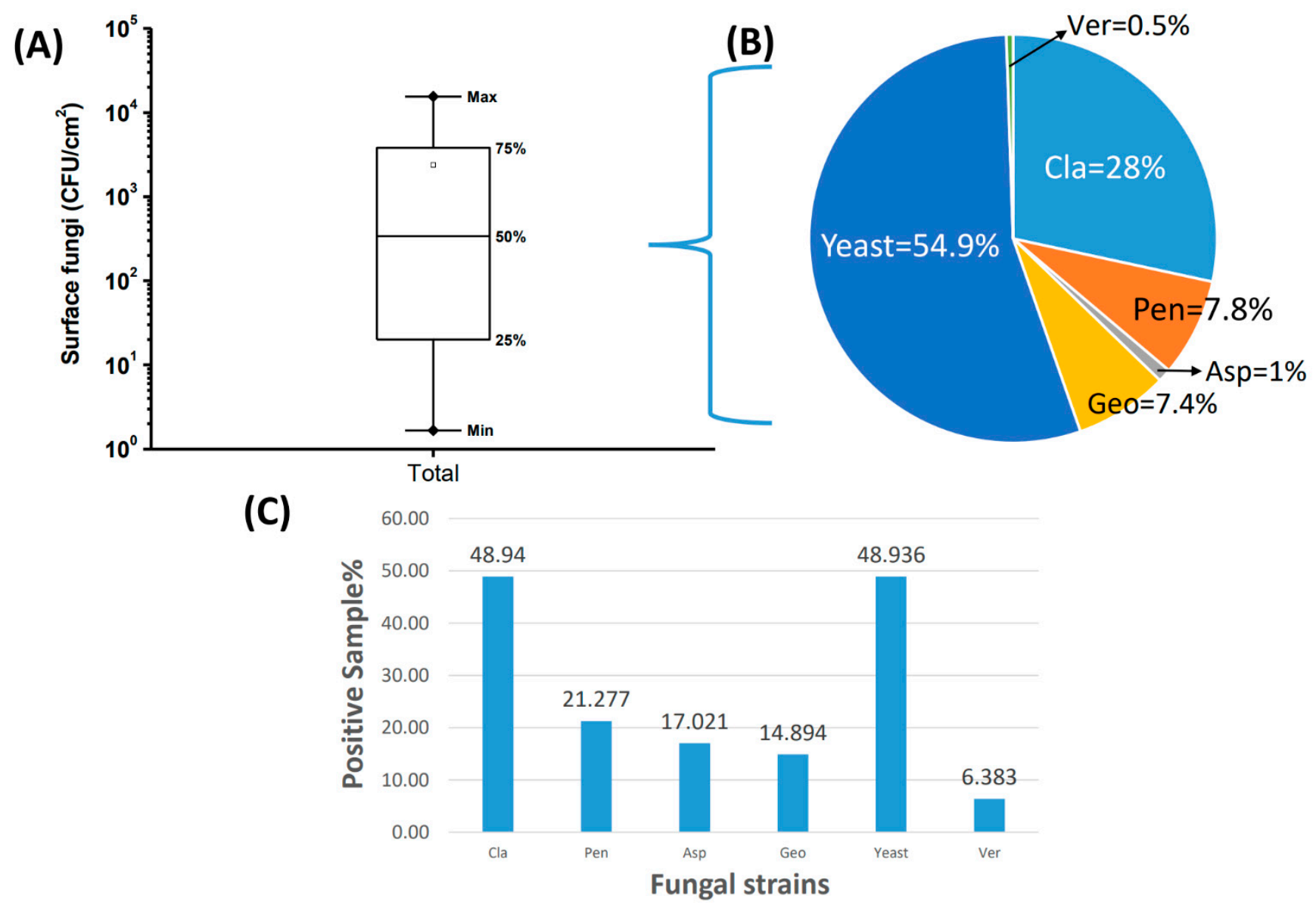

Figure 3. The distribution of the total fungal concentration $\left(\mathrm{CFU} / \mathrm{cm}^{2}\right)$ on the wall surface of household samples (A). The percentage shown in the pie chart (B) is the concentration distribution of individual fungal genera among the total surface fungi. The bar chart (C) shows the \% positive samples having the respective fungal genera on household wall surfaces where visible mold spots were observed $(n=47)$. Cla = Cladosporium; Pen = Penicillium; Asp = Aspergillus; Geo = Geotrichum; Ver $=$ Verticillium; Total $=$ total fungi.

Table 1. Spearman's rank correlation coefficient with environmental parameters and fungal concentrations in the indoor air.

\begin{tabular}{ccccccccc}
\hline & \multicolumn{2}{c}{ Temperature $^{*}$} & \multicolumn{2}{c}{ Atmospheric $\mathbf{R H}^{*}$} & \multicolumn{2}{c}{ Wind Speed } & \multicolumn{2}{c}{$\mathrm{CO}_{\mathbf{2}}$} \\
\cline { 2 - 8 } & $\mathbf{r}$ & $p$ & $\mathbf{r}$ & $p$ & $\mathbf{r}$ & $p$ & $\mathbf{r}$ & $p$ \\
\hline Cladosporium spp. & $0.195^{*}$ & 0.048 & -0.149 & 0.133 & 0.094 & 0.345 & $-0.200^{*}$ & 0.042 \\
Penicillium spp. & -0.064 & 0.524 & $0.397^{* *}$ & $<0.0001$ & -0.020 & 0.842 & 0.023 & 0.819 \\
Aspergillus spp. & 0.063 & 0.525 & 0.118 & 0.235 & -0.156 & 0.116 & $-0.279^{* *}$ & 0.004 \\
Fusarium spp. & $0.205^{*}$ & 0.038 & $-0.274^{* *}$ & 0.005 & -0.001 & 0.992 & $-0.419^{* *}$ & $<0.0001$ \\
Geotrichum spp. & 0.028 & 0.783 & 0.062 & 0.532 & -0.054 & 0.586 & 0.010 & 0.922 \\
Yeast & -0.016 & 0.874 & -0.157 & 0.114 & 0.070 & 0.485 & 0.038 & 0.702 \\
Verticillium spp. & $0.247^{*}$ & 0.012 & $-0.269^{* *}$ & 0.006 & $0.237^{*}$ & 0.016 & $-0.246^{*}$ & 0.012 \\
Total fungi & 0.144 & 0.148 & -0.026 & 0.798 & 0.156 & 0.115 & $-0.273^{* *}$ & 0.005 \\
\hline
\end{tabular}

$\mathrm{N}=103,{ }^{*} p<0.05,{ }^{* *} p<0.01,{ }^{*}$ Temperature $=$ Atmospheric Temperature, ${ }^{\#} \mathrm{RH}=$ Relative humidity.

\subsection{Correlation among Environmental Parameters and Surface Fungal Density}

The correlations among the environmental parameters (surface temperature, surface $\mathrm{RH}$, wind speed, and $\mathrm{CO}_{2}$ ) and surface fungal concentrations in the indoor environment are shown in Table 2. Because Fusarium was not observed on the surfaces of indoor environments, no correlation result is shown for Fusarium in Table 2. On the environmental surfaces, no correlations were observed between fungi and temperature. Only Geotrichum and Verticillium were correlated with surface $\mathrm{RH}$, and the total fungi were negatively 
correlated with wind speed. In addition, the surface densities of yeast and total fungi were significantly correlated with $\mathrm{CO}_{2}$ concentrations.

Table 2. Spearman's rank correlation coefficient with environmental parameters and fungal concentrations on the surface.

\begin{tabular}{ccccccccc}
\hline & \multicolumn{2}{c}{ Surface Tem ${ }^{\#}$} & \multicolumn{2}{c}{ Surface $\mathbf{R H}^{*}$} & \multicolumn{2}{c}{ Wind Speed } & \multicolumn{2}{c}{$\mathbf{C O}_{2}$} \\
\cline { 2 - 10 } & $\mathbf{r}$ & $\boldsymbol{p}$ & $\mathbf{r}$ & $\boldsymbol{p}$ & $\mathbf{r}$ & $\boldsymbol{p}$ & $\mathbf{r}$ & $\boldsymbol{p}$ \\
\hline $\begin{array}{c}\text { Cladosporium } \\
\text { spp. }\end{array}$ & 0.1571 & 0.113 & 0.0344 & 0.730 & -0.1073 & 0.281 & -0.0050 & 0.960 \\
Penicillium spp. & 0.1573 & 0.112 & 0.1802 & 0.069 & -0.0636 & 0.523 & -0.0130 & 0.896 \\
Aspergillus spp. & 0.0807 & 0.418 & 0.0435 & 0.663 & -0.0915 & 0.358 & 0.0610 & 0.541 \\
Geotrichum spp. & 0.1050 & 0.291 & $0.2325^{*}$ & 0.018 & -0.0275 & 0.783 & 0.0117 & 0.907 \\
$\quad$ Yeast & -0.073 & 0.462 & 0.1467 & 0.091 & -0.143 & 0.149 & $0.335^{* *}$ & 0.001 \\
Verticillium spp. & 0.0355 & 0.722 & $0.2425^{*}$ & 0.014 & -0.0729 & 0.464 & -0.0088 & 0.930 \\
Total fungi & 0.0934 & 0.348 & 0.1594 & 0.108 & $-0.2302 *$ & 0.019 & $0.3021^{* *}$ & 0.002 \\
\hline
\end{tabular}

$\mathrm{N}=103,{ }^{*} p<0.05,{ }^{* *} p<0.01,{ }^{\#}$ Surface Tem $=$ Surface Temperature, ${ }^{\#} \mathrm{RH}=$ Relative humidity.

\subsection{Correlation between the Concentration of Indoor and Outdoor Fungal Aerosols}

The correlation between the concentration of indoor and outdoor fungal aerosols is shown in Table 3. From the perspective of total fungi, indoor and outdoor fungal aerosol concentrations showed a significant correlation. All known indoor concentrations of individual fungi were also significantly correlated (Spearman's rank correlation coefficients ranged from 0.48 to 1 ; all $p$ values $<0.01$ ) with their outdoor concentrations. In addition, the indoor concentrations of Cladosporium were correlated with almost all the fungi (except for yeast) detected in indoor air ( $p$ values ranged from $<0.01$ to 0.019 ). Furthermore, the indoor yeast concentration was negatively correlated with almost all other indoor fungal concentrations (except for Cladosporium and Fusarium), although some correlations were not significant ( $p$ values ranged from $<0.01$ to 0.391 ).

\subsection{Correlation between the Concentrations of Airborne and Surface Fungi in Indoor Environments}

Table 4 shows the correlations between the concentrations of airborne and surface fungi in the indoor environments. Among all the surface fungi found, only Geotrichum exhibited airborne concentrations that were significantly correlated with its surface density (Spearman's rank correlation coefficient $=0.420 ; p<0.01$ ). However, when only surface fungi were compared, the densities of almost all fungal genera were significantly correlated with each other (except for yeast), with Spearman's rank correlation coefficients ranging from 0.30 to 0.70 (all $p$ values $<0.01$ ). For the surface yeast, the concentration was consistently non-significantly correlated with that of other fungal strains on the surface ( $p$ values ranged from 0.076 to 0.596 ).

\subsection{Association among the Airborne Fungal Concentration, Fungal Surface Area Ratio, and Environmental Parameters}

In Table 5, we divided the fungal surface ratio into three levels (0, 0-0.00031, and 0.00031-1), based on the median of our data (Supplementary Material). Next, we included three environmental factors that may affect the concentration of airborne fungi in the multiple linear regression model for analysis adjustment. Using the model, we found that if a higher surface area ratio (0.00031-1) appeared in the environment, the indoor air would present a significantly higher concentration of Aspergillus and Geotrichum aerosols than the reference group (surface ratio $=0$ ). In addition, a dose-dependent response was also observed for Aspergillus and Geotrichum, and only the highest level 3 surface area ratio contributed to a significantly higher indoor air concentration (139\% for Aspergillus, $p=0.005$, and $85 \%$ for Geotrichum, $p=0.014$ ) than the reference group. The level 2 surface ratio increased airborne Verticillium concentrations by $39.8 \%$ compared to the reference group. However, this correlation was not significant for Verticillium $(p=0.108)$. 
Table 3. Spearman's rank correlation coefficient with airborne fungal concentrations in the indoor and outdoor air.

\begin{tabular}{|c|c|c|c|c|c|c|c|c|c|c|c|c|c|c|c|c|}
\hline & $\mathrm{ID}^{\#}$ cla & ID pen & ID asp & ID fus & ID geo & $\begin{array}{c}\text { ID } \\
\text { Yeast }\end{array}$ & ID ver & $\begin{array}{l}\text { ID } \\
\text { Total }\end{array}$ & $\begin{array}{c}\text { OD }^{\#} \\
\text { cla }\end{array}$ & OD pen & OD asp & OD fus & OD geo & $\begin{array}{c}\text { OD } \\
\text { Yeast }\end{array}$ & OD ver & $\begin{array}{c}\text { OD } \\
\text { Total }\end{array}$ \\
\hline ID cla & 1.000 & & & & & & & & & & & & & & & \\
\hline ID pen & $-0.231^{*}$ & 1.000 & & & & & & & & & & & & & & \\
\hline ID asp & 0.235 * & 0.110 & 1.000 & & & & & & & & & & & & & \\
\hline ID fus & $0.397^{* *}$ & $-0.247 *$ & 0.242 * & 1.000 & & & & & & & & & & & & \\
\hline ID geo & -0.264 & 0.141 & -0.160 & -0.061 & 1.000 & & & & & & & & & & & \\
\hline ID yeast & 0.043 & $-\underset{* *}{0.411}$ & -0.085 & 0.077 & -0.136 & 1.000 & & & & & & & & & & \\
\hline ID ver & $0.294^{* *}$ & -0.115 & -0.115 & $0.265^{* *}$ & -0.083 & -0.137 & 1.000 & & & & & & & & & \\
\hline ID total & $0.737^{* *}$ & -0.096 & 0.186 & $0.298^{* *}$ & -0.260 & $0.312 * *$ & 0.242 * & 1.000 & & & & & & & & \\
\hline OD cla & $0.716^{* *}$ & $-\underset{* *}{0.258}$ & $0.275^{* *}$ & $0.513^{* *}$ & $-0.207^{*}$ & -0.007 & $0.301^{* *}$ & $0.451^{* *}$ & 1.000 & & & & & & & \\
\hline OD pen & $\underset{* *}{-0.328}$ & 0.810 ** & 0.093 & -0.117 & $0.314^{* *}$ & $-\underset{* *}{0.456}$ & -0.134 & $-\underset{* *}{0.291}$ & -0.151 & 1.000 & & & & & & \\
\hline OD asp & $0.340^{* *}$ & -0.056 & $0.484 * *$ & $0.289^{* *}$ & $-0.250 *$ & -0.144 & 0.105 & 0.173 & $0.469^{* *}$ & -0.002 & 1.000 & & & & & \\
\hline OD fus & $0.475^{* *}$ & $-0.205^{*}$ & 0.147 & $0.585^{* *}$ & -0.082 & -0.040 & $0.222 *$ & 0.221 * & $0.640^{* *}$ & -0.028 & $0.272^{* *}$ & 1.000 & & & & \\
\hline OD geo & $\underset{* *}{-0.317}$ & 0.140 & -0.090 & -0.054 & $0.793 * *$ & -0.024 & -0.073 & $-0.223 *$ & -0.198 * & $0.256^{* *}$ & $-\underset{* *}{0.289}$ & -0.126 & 1.000 & & & \\
\hline OD yeast & 0.169 & $-\underset{* *}{0.466}$ & -0.091 & 0.113 & -0.173 & $0.697^{* *}$ & -0.071 & $0.320 * *$ & $0.219 *$ & $-\underset{* *}{-0.467}$ & 0.049 & 0.149 & -0.214 * & 1.000 & & \\
\hline OD ver & $0.294^{* *}$ & -0.116 & -0.114 & $0.265^{* *}$ & -0.083 & -0.137 & $1.000^{* *}$ & $0.242 *$ & $0.301^{* *}$ & -0.134 & 0.105 & $0.222 *$ & -0.073 & -0.071 & 1.000 & \\
\hline OD total & 0.670 ** & -0.210 * & $0.321^{* *}$ & $0.525^{* *}$ & -0.112 & 0.131 & $0.231 *$ & $0.583^{* *}$ & $0.856^{* *}$ & -0.149 & $0.504^{* *}$ & $0.571^{* *}$ & -0.124 & 0.430 ** & 0.231 * & 1.000 \\
\hline
\end{tabular}


Table 4. Spearman's rank correlation coefficient with the fungal concentrations in the indoor air and on the surface.

\begin{tabular}{|c|c|c|c|c|c|c|c|c|c|c|c|c|c|c|}
\hline & ID $^{\#}$ cla & ID pen & ID asp & ID geo & ID yeast & ID ver & ID Total & $\mathrm{SF}^{\#}$ cla & SF pen & SF asp & SF geo & SF Yeast & SF ver & SF Total \\
\hline ID cla & 1.000 & & & & & & & & & & & & & \\
\hline ID pen & $-0.231 *$ & 1.000 & & & & & & & & & & & & \\
\hline ID asp & 0.235 * & 0.110 & 1.000 & & & & & & & & & & & \\
\hline ID yeast & 0.043 & $-0.411^{* * *}$ & -0.085 & -0.136 & 1.000 & & & & & & & & & \\
\hline ID ver & $0.294^{* *}$ & -0.115 & -0.115 & -0.083 & -0.137 & 1.000 & & & & & & & & \\
\hline ID total & $0.737^{* *}$ & -0.096 & 0.186 & $-0.260 * *$ & $0.312^{* *}$ & 0.242 * & 1.000 & & & & & & & \\
\hline SF cla & 0.063 & 0.109 & $0.295^{* *}$ & 0.181 & 0.002 & -0.010 & 0.197 * & 1.000 & & & & & & \\
\hline SF asp & -0.013 & -0.087 & 0.081 & 0.184 & -0.043 & 0.137 & -0.047 & $0.300^{* *}$ & $0.424 * *$ & 1.000 & & & & \\
\hline SF geo & $-0.303^{* *}$ & $0.282^{* *}$ & 0.095 & $0.420 * *$ & 0.014 & -0.054 & -0.054 & $0.504^{* *}$ & $0.704^{* *}$ & $0.389 * *$ & 1.000 & & & \\
\hline SF yeast & 0.061 & 0.003 & -0.057 & 0.101 & 0.051 & 0.009 & 0.052 & -0.176 & 0.053 & -0.154 & -0.143 & 1.000 & & \\
\hline SF ver & -0.198 * & $0.271^{* *}$ & 0.105 & $0.361^{* *}$ & 0.065 & -0.035 & -0.029 & $0.389^{* *}$ & $0.563^{* *}$ & $0.402 * *$ & $0.655^{* *}$ & -0.089 & 1.000 & \\
\hline SF total & 0.108 & 0.032 & 0.131 & $0.269 * *$ & 0.078 & 0.020 & 0.176 & $0.537^{* *}$ & $0.401^{* *}$ & 0.291 ** & $0.312^{* *}$ & $0.623^{* *}$ & $0.303^{* *}$ & 1.000 \\
\hline
\end{tabular}

Table 5. Association among the airborne fungal concentration, fungal surface area ratio and environmental parameters determined by multiple linear regression model.

\begin{tabular}{|c|c|c|c|c|c|c|c|c|}
\hline & \multirow{2}{*}{$\mathbf{N}$} & $\mathrm{ID}^{\#}$ cla & ID pen & ID $a s p$ & ID geo & ID Yeast & ID ver & ID Total \\
\hline & & \multicolumn{7}{|c|}{ Percent Changes $(\beta \pm S E)$} \\
\hline Surface area ratio & & & & & & & & \\
\hline Level 1:0 & 56 & Reference & Reference & Reference & Reference & Reference & Reference & Reference \\
\hline Level 2: $\leq$ Median $(>0-0.00031)$ & 24 & $-8.11 \pm 37.14$ & $-55.42 \pm 58.10$ & $61.0 \pm 34.94$ & $23.63 \pm 27.49$ & $10.86 \pm 76.8$ & $39.8 \pm 22.92$ & $7.5 \pm 22.73$ \\
\hline Level 3: > Median (0.00031-1) & 23 & $33.02 \pm 38.02$ & $112.19 \pm 59.57$ & $138.8 \pm 35.7 * *$ & $85.5 \pm 28.12$ * & $1.39 \pm 78.88$ & $2.53 \pm 23.44$ & $39.03 \pm 23.24$ \\
\hline Atmospheric Temperature & 103 & $11.68 \pm 7.22$ & $5.62 \pm 10.63$ & $4.37 \pm 6.83$ & $1.24 \pm 5.5$ & $-4.42 \pm 13.40$ & $4.61 \pm 4.66$ & $10.33 \pm 4.62 *$ \\
\hline Atmospheric humidity & 103 & $-0.33 \pm 1.46$ & $7.76 \pm 2.13^{* *}$ & $1.31 \pm 1.39$ & $0.19 \pm 1.12$ & $-3.81 \pm 2.65$ & $-1.46 \pm 0.95$ & $1.21 \pm 0.94$ \\
\hline $\mathrm{CO}_{2}$ & 103 & $-0.05 \pm 0.07$ & $-0.04 \pm 0.10$ & $-0.23 \pm 0.06^{* *}$ & $-0.03 \pm 0.05$ & $0.03 \pm 0.12$ & $-0.08 \pm 0.04$ & $-0.12 \pm 0.04^{* *}$ \\
\hline
\end{tabular}

${ }^{*} p<0.05 * * p<0.01,{ }^{*} \mathrm{ID}=$ Indoor air, cla $=$ Cladosporium $;$ pen $=$ Penicillium; asp $=$ Aspergillus; geo $=$ Geotrichum $;$ ver $=$ Verticillium; total $=$ total fungi. 


\section{Discussion}

Fungal sampling in this study was conducted in summer. A number of studies have shown that the concentration of airborne fungi in summer is higher than that in winter [13-15]. Although the concentration of fungi found in southern Taiwan in winter was higher than that in summer [16], the sampling sites in this study were evenly distributed throughout Taiwan, and seasonal changes in airborne fungal concentrations were not the major focus of this study. In general, the temperature and humidity measured in previous similar fungal studies were within the measured range of our results $[7,13,16]$. In addition, only nine airborne samples exceeded $1000 \mathrm{ppm}$ of $\mathrm{CO}_{2}$ concentration in the indoor air, which is the stipulated standard of Taiwan's indoor air quality management act.

The most predominant airborne fungal genera in our study agreed with those in previous studies conducted in Taiwan [7,13], except for the difference in the predominant ranking of fungi. However, Cladosporium, Penicillium, and Aspergillus always appeared to be predominant in air sampling [17]. In addition, the airborne concentrations of these predominant fungal genera, including Cladosporium, yeast, Penicillium, Fusarium, and Aspergillus, were also similar to a previous study's findings of $10^{0}$ to $10^{2} \mathrm{CFU} / \mathrm{m}^{3}$ [14]. Cladosporium usually dominated among all airborne fungi in indoor and outdoor air. Since Cladosporium is a well-known genus from the outdoor environment, a previous study demonstrated that the I/O ratio of Cladosporium might be less than 1 [18] (median $=0.91$ in our study). Another fungal genus that may arise outdoors is Penicillium, which is associated with soil and plants. However, the I/O ratio of Penicillium was often greater than 1 [14] (median $=1.002$ in our study). Obviously, there is Penicillium contamination in an indoor environment when the $\mathrm{I} / \mathrm{O}$ ratio is greater than 1 , but contamination sources are rarely found.

For surface sampling, we collected data only from residential environments, but the most predominant fungal genera were also found on other indoor environmental surfaces, including those in green groceries, butcheries, houses, public restrooms, and laboratories [19]. Although commonly found surface fungi, including Cladosporium, Penicillium, and Aspergillus [19,20], are also frequently found in indoor air, fewer fungal genera were observed on the surface than in the air. Most surface sampling was only conducted for qualitative or semiquantitative analysis (no surface area available) for the identification of fungal genera. It would be difficult to directly compare the fungal densities on different surfaces. Compared to some dry regions with low rainfall, yeasts that appear in the environment may be related to the warm and humid climate in Taiwan. A previous study also demonstrated that yeasts may appear on relatively damp surfaces, such as bathroom sinks and bathtub drains [8].

This study investigated the four most important factors affecting indoor fungal concentrations, including temperature, $\mathrm{RH}$, wind speed, and $\mathrm{CO}_{2}$ concentration. In general, the optimum temperature for different fungal taxa varies from 25 to $30{ }^{\circ} \mathrm{C}$ [21]. The results obtained for three airborne fungi are consistent with previous findings that airborne fungal concentrations are significantly positively correlated with temperature [17,22-24]. The growth of fungi as temperatures increase may also increase the bioavailability of airborne fungal allergens [24]. However, the concentration of surface fungi did not increase significantly with increasing surface temperature. We speculate that the conflicting results between air and surface samples may result from the smaller variation in surface temperature (coefficient of variation $\% ; C V=5.1 \%$ ) than that of atmospheric temperature $(\mathrm{CV}=6.7 \%)$. In addition, the World Health Organization (WHO) guidelines also indicate that common indoor temperatures may not be a limiting factor for fungal growth but may affect the growth rate [25]. In addition to the effect of temperature, we also found that $\mathrm{RH}$, wind speed, and $\mathrm{CO}_{2}$ all have different correlations with airborne and surface fungi. $\mathrm{RH}$ is an important limiting factor for fungal growth, and most fungi may not grow below an $\mathrm{RH}$ of $75-80 \%[25,26] . \mathrm{CO}_{2}$, an indicator of the ventilation rate, was negatively correlated with fungal concentrations, since air convection may change the fungal profile in air [27]. Conversely, $\mathrm{CO}_{2}$ may also promote the growth of specific fungi on the surface, 
such as Aspergillus spp. [28,29]. For the influence of wind speed, wind speed may accelerate changing the type and concentration of airborne fungi indoors, but it may also take away surface fungal spores and then reduce their concentration. The environmental factors investigated in this study may have different effects on air and surface fungi. However, the conflicting correlation results between airborne and surface samples may also result from the limitations of air and surface sampling technology. For example, the time for air sampling rarely exceeds $15 \mathrm{~min}$ and cannot represent a long-term fungal profile in the air [25]. The concentration and species profile of airborne fungi may vary rapidly [25]. Although surface sampling is considered less affected by temporal variation, it still cannot represent the airborne fungal concentration.

Taking into account the $\mathrm{I} / \mathrm{O}$ ratios, higher fungal concentrations in outdoor air than in indoor air may reveal an exogenous source of indoor contamination. Cladosporium is a well-known outdoor genus with relatively constant concentrations year-round [7,8,16,19]. In addition, Cladosporium, Aspergillus, and Fusarium have been found to attach to the surfaces of plant leaves and may produce spores that float into the air [30]. Geotrichum (median $\mathrm{I} / \mathrm{O}=0.98$ ) and Verticillium (median $\mathrm{I} / \mathrm{O}=0.78$ ) not only exist in outdoor soil and plants but are also common plant pathogens [31,32]. Although Penicillium is also associated with soil and plants [16,30], it can still be found to originate in indoor sources since it can grow wherever organic material is available with very low water content [19]. For yeast, the median I/O ratio was greater than 1 (1.56), indicating that there may be an endogenous contamination source of indoor air. The indoor yeast concentration was negatively correlated with almost all molds but only positively correlated with Cladosporium and Fusarium. The correlation between yeast and Fusarium may be related to the water activity (Aw). Other molds, such as Penicillium and Aspergillus, are considered to have lower Aw values ( 0.85 or less) and therefore should be drought tolerant [33]. In contrast, both Fusarium and yeast grown at an Aw above 0.90 require higher amounts of available water [33,34].

In Table 4, it can be seen that the surface densities of individual fungi had no significant correlation with the corresponding airborne concentrations, except for those of Geotrichum. A previous study indicated that spores produced by specific molds cannot be easily aerosolized because of their sticky nature [4]. The dry spores produced by Cladosporium, Penicillium, and Aspergillus may have more chances to be propelled into the air. However, the recommendation by the previous study was based on the number of visible mold spots to predict air concentrations, not the mold density on the surface per area. Theoretically, the higher the concentration of surface fungi that can produce dry spores, the higher the air fungal concentration. A significant correlation was only observed for Geotrichum, which is a fast growing fungus with a powdery texture, whose dry spores can easily disperse through the air $[35,36]$. Researchers also found that Geotrichum can limit Fusarium growth because of available resource competition [35], and we did not find Fusarium on any surface in the current study. For other fungi, the low correlation between the surface and airborne fungal concentrations may be related to the fact that the naked eye can only observe mold spots of a certain size. In addition, some fungi growing at high Aw levels (such as yeast) tend to grow on relatively humid surfaces, and this kind of surface type and structure might have an impact on spore formation and therefore affect spore flux $[4,37]$.

As shown in Table 5, we attempted to determine whether the ratio of the area of mold spots to the total house area would significantly contribute to a higher indoor fungal concentration. If there was a higher mold surface ratio $(>0.00031)$ in the total area of an indoor environment, then there could be a higher airborne concentration of Aspergillus or Geotrichum. Aspergillus and Geotrichum may generate dry spores from surface mold spots, and these spores tend to proliferate from air to other organic compounds, such as food, paper, and dust, among others. Compared to Geotrichum, Aspergillus has received more attention because of its serious health impact [24]. Aspergillus species are commonly saprophytic fungi in nature, with small $(2-3 \mu \mathrm{m})$ spores, and the concentration of 
Aspergillus spp. can significantly increase after a typhoon event [38]. We originally expected that Cladosporium and Penicillium, which have dry spores, might also contribute to higher indoor concentrations. However, the result was the same as that shown in Table 4. In terms of surface density and the surface area ratio, the airborne concentrations of Cladosporium and Penicillium contributed by surface molds may be quite limited. This phenomenon may be related to the small sizes of some mold spots of Cladosporium or Penicillium, which are too small to observe. Moreover, all our sampling families had children, so parents may have frequently cleaned up obviously visible mold spots.

Airborne Verticillium species are often found in agricultural areas, indoor environments, waste composting facilities, and even during Asian dust periods in Taiwan [39-41]. For Verticillium, the surface area ratio at level 2 (0-0.00031) may be related to the airborne concentration. However, this correlation was insignificant. Although we mainly explored the correlation between surface mold area and the concentration of airborne fungi, moldinfested surfaces may release more than spores into the air; a previous study also found that fungi on the surface of kitchens and showers may release volatile organic compounds into the air [42]. Thus, the appearance of surface mold affects human health and is worthy of further study. Conversely, we did not find a common fungus in Taiwan, Alternaria spp. A previous study indicated that Alternaria is related to agricultural plants [43]; thus, there may have been fewer opportunities to collect Alternaria as our sampling sites were mainly in residential areas. Another possible explanation is that we applied the culture assay for fungal quantification. The disadvantage of the culture method is that it may underestimate the viable fungal concentration, so that samples of Alternaria may be unavailable. Currently, several DNA-based methods, such as polymerase chain reaction (PCR), are available, but these methods may not distinguish dead or viable fungal cells without support from other technologies. Consequently, the microscopic method applied in this study maybe a complementary assay to culture-based methods for further identification of fungi.

Our study results recommend determining the surface area of visible mold spots, which may be important since a larger area of mold spot may be related to the airborne concentration of certain fungi. Quantifying areas by counting the number of pixels in a digital image has already been used in ecological and environmental studies [44,45]. Compared to manual quantification, the advantage of this method is that some irregular surface areas can be quickly quantified. However, there are some limitations of our study. First, some spores from the surface may not stick to the swab; therefore, the surface fungal concentration may be underestimated. Second, when observing the mold spot on site, if it is too small or white in color, it may be accidentally overlooked by the sampling personnel. Finally, young colonies and the colony margins of several Aspergillus and Penicillium species have a white color; therefore, the surface areas determined by digital image quantification can be underestimated.

\section{Materials and Methods}

\subsection{Sampling Locations}

This study involved several major cities in northern, middle, southern, and eastern Taiwan, including Taipei, Hsinchu, Yunlin, Chiayi, Tainan, Kaohsiung, and Taitung, with a total of 52 living environments being studied from June to September. The participating households all responded by questionnaire that there were visible mold spots on the walls of their houses.

\subsection{Airborne Fungus Measurements}

At each sampling site, fungal aerosol samples were collected in triplicate using an Andersen 1-STG impactor (Andersen Samplers, Inc., Atlanta, GA, USA). The pump and sampling apparatus were placed in the living room, bedroom, and outside entrance of each home. Among all the households included for indoor sampling, one had two master bedrooms and therefore had two bedroom samples. In another four households, because there was no obvious partition wall between the living room and the bedroom (studio 
apartment), only living room samples were collected. The sampling height was $1.2 \mathrm{~m}$ above the floor, within the breathing zone of individuals, at each location. The Andersen impactor was operated for 5 min with malt extract agar plates (MEAs) at a sampling flow rate of $28.3 \mathrm{~L} / \mathrm{min}$. All evaluated MEA plates collected from the field were placed in an incubator at $25{ }^{\circ} \mathrm{C}$ for 5 days. The fungal culture method recommended by the American Conference of Governmental Industrial Hygienists (ACGIH) was performed at room temperature $\left(18{ }^{\circ} \mathrm{C}\right.$ to $\left.22{ }^{\circ} \mathrm{C}\right)$ [1]. In this study, we followed the standard method proposed by the Environmental Protection Administration in Taiwan (NIEA E401.15C) using MEA plates, which were incubated at $25^{\circ} \mathrm{C}$ for 5 days. This incubation temperature has also been applied in previous studies $[7,9,16]$. Finally, the airborne fungal concentration presented in $\mathrm{CFU} / \mathrm{m}^{3}$ was calculated based on the colony number, sampling time, and flow rate. For fungal species identification, all colony samples recovered from the MEA plates were subjected to lactophenol cotton blue staining and then identified under a microscope following the clinical laboratory handbook [46]. The reported genera included at least Aspergillus, Penicillium, Cladosporium, Fusarium, Geotrichum, Verticillium, and yeast. To increase the chance of collecting a variety of molds in the air, we collected three samples at each location. After cultivation, we determined the total counts of individual mold colonies recovered from the three agar plates and calculated their airborne concentrations separately.

\subsection{Surface Sampling and Sampling Area Counting}

During the sampling period, visible molds on the surfaces of living room or bedroom walls were selected for swab sampling. Surface sampling was performed using a sterile water-moistened swab, and the surface was rubbed for $5 \mathrm{~s}$. Subsequently, swabs were placed in a $2 \mathrm{~mL}$ tube containing $0.1 \%$ Tween 80 buffer and immediately transferred for culture. Aliquots $(0.1 \mathrm{~mL})$ of the liquid samples from the tubes were diluted 10- to 100-fold, plated on MEA plates, and then incubated for 5 days at $25^{\circ} \mathrm{C}$. Finally, the total colony counts of the target surfaces were calculated based on the dilution ratio, and the colony counts were adjusted by the surface areas to present the results in CFU $/ \mathrm{cm}^{2}$. To quantify the sampling area, we calculated the target surface pixels in digital images, a method that has been applied to measure the area of a single leaf and hospital surfaces in ecological and environmental studies $[44,47]$. Briefly, we placed a reference paper beside the target surface and took a digital picture (Figure 4A). While taking the picture, the angle between the wall surface and camera was aimed vertically at the target center. Therefore, we obtained a picture including the reference paper and surface of interest and then directly calculated the pixel numbers in Photoshop. The procedure to calculate the pixel numbers in Photoshop is demonstrated in Figure 4.

The surface area of interest was calculated via the following Equation:

$$
\frac{\mathrm{A}_{\text {surface }}}{\mathrm{A}_{\text {reference paper }}}=\frac{\mathrm{N}_{\text {surface }}}{\mathrm{N}_{\text {reference paper }}}
$$

where $\mathrm{A}_{\text {surface }}$ and $\mathrm{A}_{\text {reference paper }}$ are the areas of the target surface and reference paper, respectively, and $\mathrm{N}_{\text {surface }}$ and $\mathrm{N}_{\text {reference paper }}$ are the pixel numbers of the target surface and reference paper counted in Photoshop within the same picture, respectively (Figure 5). 


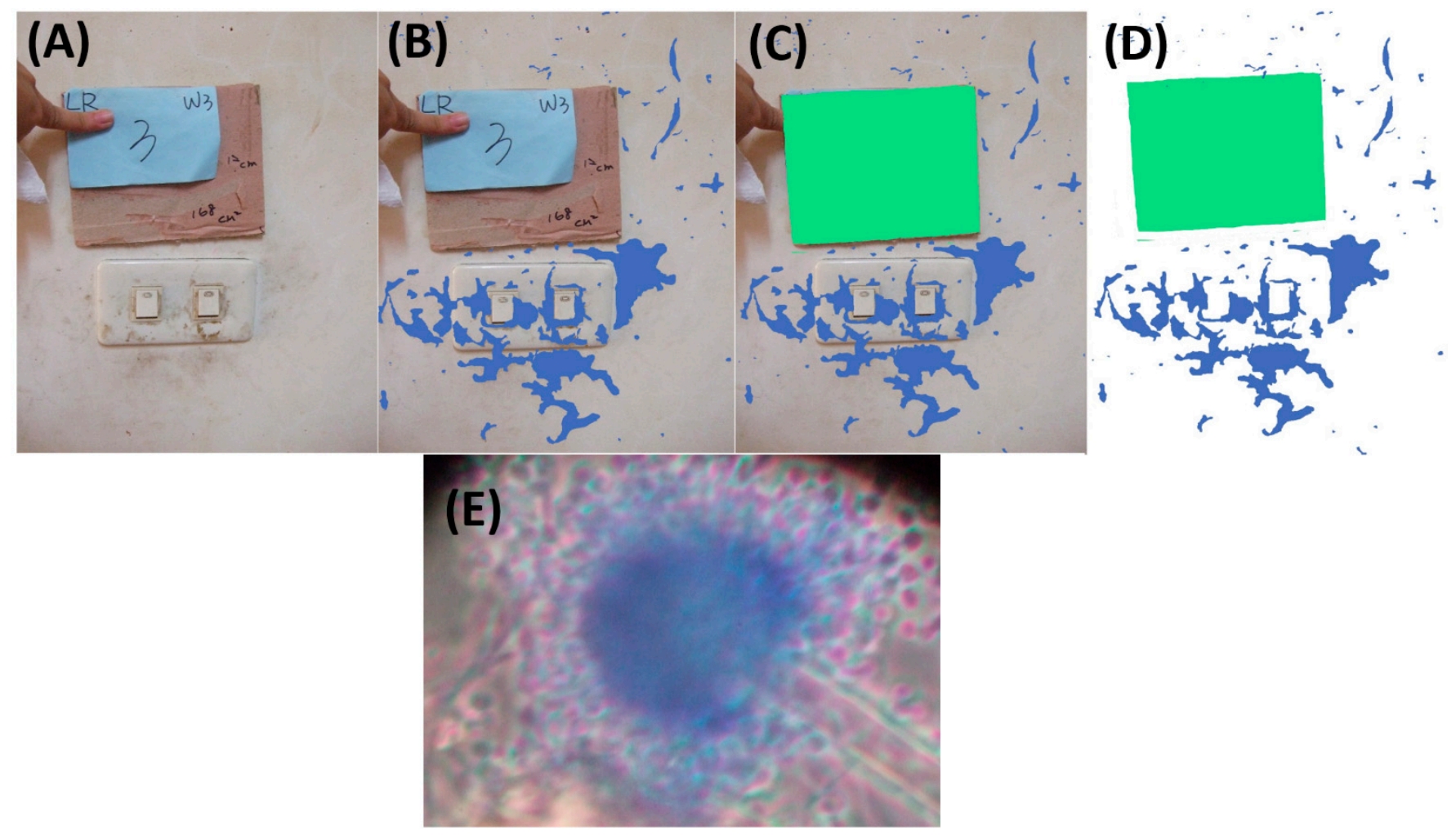

Figure 4. Field photo used to illustrate calculation of pixel numbers. (A) Raw picture of the wall surface. (B) Selection of each target spot as an individual layer (color blue). Subsequently, all layers of independent mold spots were combined, and the total pixels were counted using the software. (C) The reference paper was selected as another individual layer, and the pixels were counted using the software (color green). (D) Equation (1) was used to calculate the surface mold area. (E) The surface mold recovered from the MEA plate was subjected to lactophenol cotton blue staining and then identified as Aspergillus spp. by microscopic observation.
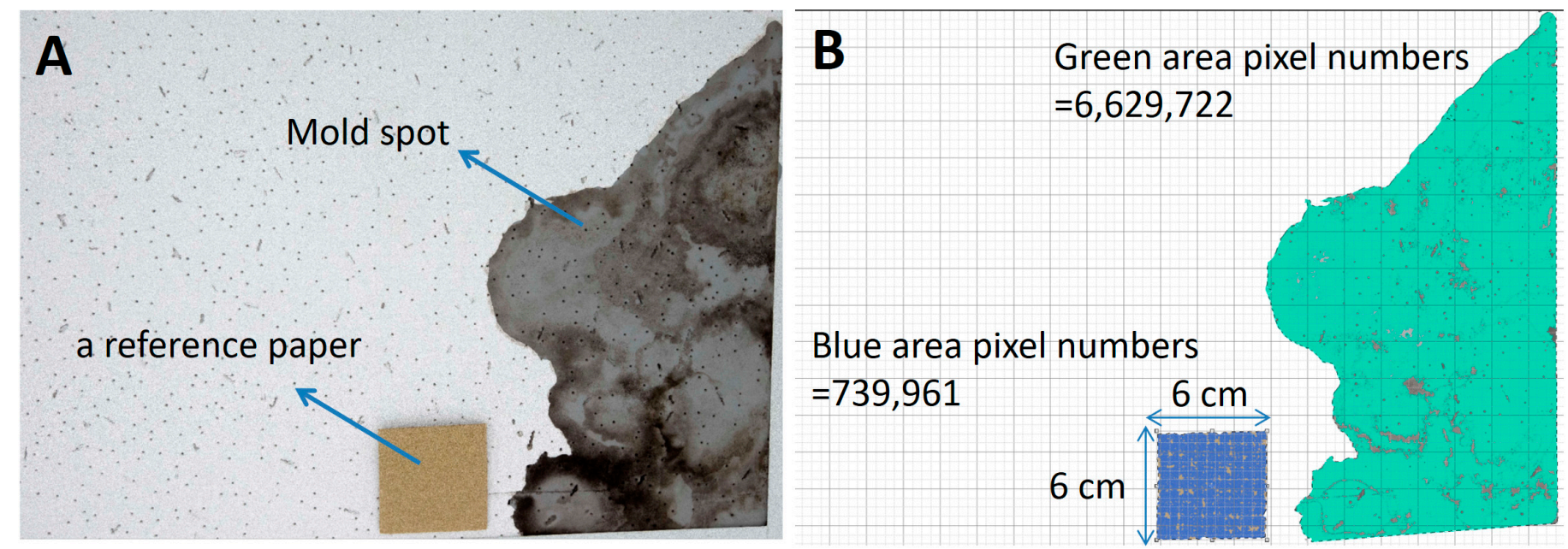

Figure 5. Raw (A) and processed (B) pictures were used to calculate the surface area of visible mold spots on wall surfaces. The number of pixels in the reference paper $\left(6 \times 6 \mathrm{~cm}^{2}\right)$ and the surface of the mold were calculated using the processed photographs (B). The surface mold spot area in picture B is approximately $323 \mathrm{~cm}^{2}$, based on Equation (1) and described in the methods section. 


\subsection{Other Environmental Parameter Measurements}

The temperature, atmospheric relative humidity (RH), and concentration of carbon dioxide $\left(\mathrm{CO}_{2}\right)$ were recorded using a KD AirBoxx real-time instrument (KD Engineering, Inc., Blaine, WA, USA) in all sampling locations. In addition to atmospheric RH, we also measured the surface temperature and moisture content of the target surface where visible molds appeared using an HP23-AW handheld instrument (Rotronic AG, Bassersdorf, Swiss). Conversely, the wind speed was measured using an air velocity meter (TSI 9535, Shoreview, MN, USA)

\subsection{Statistical Analysis}

Differences in airborne fungal concentrations between different sampling locations were determined by the Wilcoxon signed rank test. For the individual pairwise correlations between environmental parameters and airborne/surface fungal concentrations, Spearman's rank correlation model was constructed. Finally, to further explore the correlation between the mold surface areas and their concentrations in the air, a multiple linear regression model was constructed. A natural logarithm transformation (ln-transformation) of airborne fungal concentration was performed before conducting the analyses. The corresponding regression coefficients were back-transformed $\left(100 \times\left(\mathrm{e}^{\beta}-1\right)\right)$ to obtain the percent changes. The limit of detection (LOD) was $2.36 \mathrm{CFU} / \mathrm{m}^{3}$ for airborne fungal samples and $1.33 \mathrm{CFU} / \mathrm{cm}^{2}$ for surface samples. The airborne or surface samples with individual fungal concentrations below the LOD were assigned a value of one-third of the LOD for the statistical analyses.

\section{Conclusions}

Rapid monitoring of fungi is important for evaluating the related health risks and maintaining good indoor air quality. This study demonstrated that the indoor air concentration of individual fungi is significantly correlated with the outdoor air concentration. Regarding the contribution of surface fungi to indoor air concentrations, the density of individual fungi on the surface had no significant correlation with indoor air concentrations, except for Geotrichum. However, for some specific genera, including Aspergillus and Geotrichum, the surface area of visible mold spots was significantly related to their airborne concentration indoors. These results indicate the need to focus attention on visible mold spots on surfaces, which may contain fungal spores of certain allergens, such as Aspergillus, with the ability to further disperse from the surface into the air through environmental forces. In addition, this study also provides a convenient and rapid method for quantifying the area of surface mold spots. This method may be applied in future environmental monitoring or epidemiological studies.

Supplementary Materials: The following are available online at https://www.mdpi.com/article/10 $.3390 /$ pathogens10081032/s1.

Author Contributions: C.-C.T. and Y.-L.L.G. conceived and designed the current study. C.-C.T., N.H. and Y.-L.L.G. conducted the sampling and analyzed the data. C.-J.H. contributed to the study design and provided recommendations regarding this study. C.-C.H. provided sampling technical assistance. C.-C.T. and Y.-L.L.G. wrote the paper. All authors have read and agreed to the published version of the manuscript.

Funding: This research was funded by Ministry of Science and Technology, Taiwan (grant number: MOST 108-2314-B-320-004).

Institutional Review Board Statement: Not applicable.

Informed Consent Statement: Not applicable.

Data Availability Statement: The original measurement data are available in the electronic supplement. Samples with the same location ID number were collected in the same household. ID\#B indicates that sampling was conducted in the bedroom, and ID\#L represents the living room samples. 
Conflicts of Interest: The authors declare no conflict of interest.

\section{References}

1. Bioaerosols, A. Bioaerosols Assessment and Control; American Conference of Governmental Industrial Hygienists: Cincinnati, OH, USA, 1999.

2. Mebi, G.; Samuel, W.; Ojogba, M. Relationship Between Fungal Contamination of Indoor Air and Health Problems of Some Residents in Jos. In Air Quality-Monitoring and Modeling; IntechOpen: London, UK, 2012.

3. Shelton, B.G.; Kirkland, K.H.; Flanders, W.D.; Morris, G.K. Profiles of airborne fungi in buildings and outdoor environments in the United States. Appl. Environ. Microbiol. 2002, 68, 1743-1753. [CrossRef]

4. Duchaine, C.; Mériaux, A. The importance of combining air sampling and surface analysis when studying problematic houses for mold biodiversity determination. Aerobiologia 2001, 17, 121-125. [CrossRef]

5. Park, J.-H. Mold exposure and respiratory health in damp indoor environments. Front. Biosci. 2011, E3, 757-771. [CrossRef] [PubMed]

6. Mendell, M.J.; Mirer, A.G.; Cheung, K.; Tong, M.; Douwes, J. Respiratory and Allergic Health Effects of Dampness, Mold, and Dampness-Related Agents: A Review of the Epidemiologic Evidence. Environ. Health Perspect. 2011, 119, 748-756. [CrossRef] [PubMed]

7. Su, H.J.; Wu, P.C.; Chen, H.L.; Lee, F.C.; Lin, L.L. Exposure Assessment of Indoor Allergens, Endotoxin, and Airborne Fungi for Homes in Southern Taiwan. Environ. Res. 2001, 85, 135-144. [CrossRef] [PubMed]

8. Adams, R.I.; Miletto, M.; Taylor, J.W.; Bruns, T.D. The Diversity and Distribution of Fungi on Residential Surfaces. PLoS ONE 2013, 8, e78866. [CrossRef] [PubMed]

9. Dallongeville, A.; LE Cann, P.; Zmirou-Navier, D.; Chevrier, C.; Costet, N.; Annesi-Maesano, I.; Blanchard, O. Concentration and determinants of molds and allergens in indoor air and house dust of French dwellings. Sci. Total Environ. 2015, 536, 964-972 [CrossRef] [PubMed]

10. Aktas, Y.D.; Ioannou, I.; Altamirano, H.; Reeslev, M.; D’Ayala, D.; May, N.; Canales, M. Surface and passive/active air mould sampling: A testing exercise in a North London housing estate. Sci. Total Environ. 2018, 643, 1631-1643. [CrossRef]

11. Khan, N.N.; Wilson, B.L. An environmental assessment of mold concentrations and potential mycotoxin exposures in the greater Southeast Texas area. J. Environ. Sci. Health Part A Toxic/Hazard. Subst. Environ. Eng. 2003, 38, 2759-2772. [CrossRef]

12. Lee, T.; Grinshpun, S.A.; Martuzevicius, D.; Adhikari, A.; Crawford, C.M.; Reponen, T. Culturability and concentration of indoor and outdoor airborne fungi in six single-family homes. Atmos. Environ. 2006, 40, 2902-2910. [CrossRef]

13. Li, C.-S.; Kuo, Y.-M. Airborne characterization of fungi indoors and outdoors. J. Aerosol Sci. 1992, 23, 667-670. [CrossRef]

14. Crawford, J.A.; Rosenbaum, P.F.; Anagnost, S.E.; Hunt, A.; Abraham, J.L. Indicators of airborne fungal concentrations in urban homes: Understanding the conditions that affect indoor fungal exposures. Sci. Total Environ. 2015, 517, 113-124. [CrossRef]

15. Bamba, I.; Azuma, M.; Hamada, N.; Kubo, H.; Isoda, N. Case Study of Airborne Fungi According to Air Temperature and Relative Humidity in Houses with Semi-Basements Adjacent to a Forested Hillside. Biocontrol Sci. 2014, 19, 1-9. [CrossRef] [PubMed]

16. Wu, P.C.; Su, H.J.; Lin, C.Y. Characteristics of indoor and outdoor airborne fungi at suburban and urban homes in two seasons. Sci. Total Environ. 2000, 253, 111-118. [CrossRef]

17. Ho, H.M.; Rao, C.; Hsu, H.H.; Chiu, Y.H.; Liu, C.M.; Chao, H.J. Characteristics and determinants of ambient fungal spores in Hualien, Taiwan. Atmos. Environ. 2005, 39, 5839-5850. [CrossRef]

18. Mui, K.W.; Chan, W.Y.; Wong, L.T.; Hui, P.S. Scoping indoor airborne fungi in an excellent indoor air quality office building in Hong Kong. Build. Serv. Eng. Res. Technol. 2010, 31, 191-199. [CrossRef]

19. Ziaee, A.; Zia, M.; Goli, M. Identification of saprophytic and allergenic fungi in indoor and outdoor environments. Environ. Monit. Assess. 2018, 190, 574. [CrossRef]

20. Beguin, H.; Nolard, N. Mould biodiversity in homes I. Air and surface analysis of 130 dwellings. Aerobiologia 1994, 10, 157-166. [CrossRef]

21. Pietikäinen, J.; Pettersson, M.; Bååth, E. Comparison of temperature effects on soil respiration and bacterial and fungal growth rates. FEMS Microbiol. Ecol. 2005, 52, 49-58. [CrossRef] [PubMed]

22. Frankel, M.; Bekö, G.; Timm, M.; Gustavsen, S.; Hansen, E.W.; Madsen, A.M. Seasonal Variations of Indoor Microbial Exposures and Their Relation to Temperature, Relative Humidity, and Air Exchange Rate. Appl. Environ. Microbiol. 2012, 78, 8289-8297. [CrossRef]

23. Wu, D.; Zhang, Y.; Tian, Y.; Li, A.; Li, Y.; Xiong, J.; Gao, R. On-site investigation of the concentration and size distribution characteristics of airborne fungi in a university library. Environ. Pollut. 2020, 261, 114138. [CrossRef]

24. van Rhijn, N.; Bromley, M. The Consequences of Our Changing Environment on Life Threatening and Debilitating Fungal Diseases in Humans. J. Fungi 2021, 7, 367. [CrossRef] [PubMed]

25. Heseltine, E.; Rosen, J. WHO Guidelines for Indoor Air Quality: Dampness and Mould; World Health Organization Regional Office for Europe: Copenhagen, Denmark, 2009.

26. Viitanen, H.; Ritschkoff, A.-C. Mould Growth in Pine and Spruce Sapwood in Relation to Air Humidity and Temperature; Swedish University of Agricultural Sciences: Uppsala, Sweden, 1991.

27. Chao, H.J.; Schwartz, J.; Milton, D.K.; A Burge, H. Populations and determinants of airborne fungi in large office buildings Environ. Health Perspect. 2002, 110, 777-782. [CrossRef] 
28. Sacks, D.; Baxter, B.; Campbell, B.C.V.; Carpenter, J.S.; Cognard, C.; Dippel, D.; Eesa, M.; Fischer, U.; Hausegger, K.; Hirsch, J.A.; et al. Multisociety Consensus Quality Improvement Revised Consensus Statement for Endovascular Therapy of Acute Ischemic Stroke. Int. J. Stroke Off. J. Int. Stroke Soc. 2018, 13, 612-632. [CrossRef]

29. Lang-Yona, N.; Levin, Y.; Dannemiller, K.; Yarden, O.; Peccia, J.; Rudich, Y. Changes in atmospheric CO2influence the allergenicity ofAspergillus fumigatus. Glob. Chang. Biol. 2013, 19, 2381-2388. [CrossRef] [PubMed]

30. Levetin, E.; Dorsey, K. Contribution of leaf surface fungi to the air spora. Aerobiologia 2006, 22, 3-12. [CrossRef]

31. Debode, J.; Van Poucke, K.; França, S.D.C.; Maes, M.; Höfte, M.; Heungens, K. Detection of Multiple Verticillium Species in Soil Using Density Flotation and Real-Time Polymerase Chain Reaction. Plant Dis. 2011, 95, 1571-1580. [CrossRef] [PubMed]

32. Pottier, I.; Gente, S.; Vernoux, J.-P.; Guéguen, M. Safety assessment of dairy microorganisms: Geotrichum candidum. Int. J. Food Microbiol. 2007, 126, 327-332. [CrossRef]

33. Bandler, R.; Stack, M.; Koch, H.; Tournas, V.; Mislivec, P. Chapter 18 Yeasts, molds, and mycotoxins. In Bacteriological Analytical Manual; Food and Drug Administration: Washington, DC, USA, 1998.

34. Belizán, M.M.; Gomez, A.D.L.A.; Baptista, Z.P.T.; Jimenez, C.M.; Matías, M.D.H.S.; Catalán, C.A.; Sampietro, D.A. Influence of water activity and temperature on growth and production of trichothecenes by Fusarium graminearum sensu stricto and related species in maize grains. Int. J. Food Microbiol. 2019, 305, 108242. [CrossRef]

35. Garbe, L.-A.; Schwarz, P.; Ehmer, A. Beer gushing. In Beer; Bamforth, C.W., Ed.; Academic Press: San Diego, CA, USA, 2009; pp. 185-212.

36. Khan, A.H.; Karuppayil, S.M. Fungal pollution of indoor environments and its management. Saudi J. Biol. Sci. 2012, 19, 405-426. [CrossRef]

37. Gopalakrishnan, S.; Devassikutty, A.K.; Mathew, M.; Ayyappan, D.; Thiagarajan, S.; Raghunathan, R. Passive Release of Fungal Spores from Synthetic Solid Waste Surfaces. Aerosol Air Qual. Res. 2016, 16, 1441-1451. [CrossRef]

38. Hsu, N.Y.; Chen, P.Y.; Chang, H.W.; Su, H.J. Changes in profiles of airborne fungi in flooded homes in southern Taiwan after Typhoon Morakot. Sci. Total Environ. 2011, 409, 1677-1682. [CrossRef] [PubMed]

39. Madsen, A.M.; Hansen, V.M.; Meyling, N.; Eilenberg, J. Human exposure to airborne fungi from genera used as biocontrol agents in plant production. Ann. Agric. Environ. Med. 2007, 14, 5-24.

40. Hameed, A.A.A.; Yasser, I.H.; Khoder, M. Indoor air quality during renovation actions: A case study. J. Environ. Monit. 2004, 6, 740-744. [CrossRef]

41. Chao, H.J.; Chan, C.C.; Rao, C.Y.; Lee, C.T.; Chuang, Y.C.; Chiu, Y.H.; Hsu, H.H.; Wu, Y.H. The effects of transported Asian dust on the composition and concentration of ambient fungi in Taiwan. Int. J. Biometeorol. 2011, 56, 211-219. [CrossRef]

42. Adams, R.I.; Lymperopoulou, D.S.; Misztal, P.K.; Pessotti, R.D.C.; Behie, S.W.; Tian, Y.; Goldstein, A.H.; Lindow, S.E.; Nazaroff, W.W.; Taylor, J.W.; et al. Microbes and associated soluble and volatile chemicals on periodically wet household surfaces. Microbiome 2017, 5, 128. [CrossRef] [PubMed]

43. Lee, H.B.; Patriarca, A.; Magan, N. Alternaria in Food: Ecophysiology, Mycotoxin Production and Toxicology. Mycobiology 2015, 43, 93-106. [CrossRef]

44. Chen, B.; Fu, Z.; Pan, Y.; Wang, J.; Zeng, Z. Single Leaf Area Measurement Using Digital Camera Image. In Computer and Computing Technologies in Agriculture IV; Li, D., Liu, Y., Chen, Y., Eds.; Springer: Berlin/Heidelberg, Germany, 2011; Volume 345, pp. 525-530.

45. Chaudary, P.; Godara, S. Fast and Accurate Method for Leaf Area Measurement. Int. J. Comput. Appl. 2012, 49, 22-25. [CrossRef]

46. St-Germain, G.; Summerbell, R. Identifying Filamentous Fungi: A Clinical Laboratory Handbook; Star Publishing Company: Singapore, 1996.

47. Ho, Y.H.; Wang, L.S.; Jiang, H.L.; Chang, C.H.; Hsieh, C.-J.; Chang, D.C.; Tu, H.Y.; Chiu, T.Y.; Chao, H.J.; Tseng, C.C. Use of a Sampling Area-Adjusted Adenosine Triphosphate Bioluminescence Assay Based on Digital Image Quantification to Assess the Cleanliness of Hospital Surfaces. Int. J. Environ. Res. Public Health 2016, 13, 576. [CrossRef] [PubMed] 